\title{
Block Copolymers between Styrene and Isobutylene by a Direct Route
}

\author{
Paolo GIUSTI \\ Istituto di Chimica Industriale ed Applicata, Facoltà di Ingegneria, \\ Università di Pisa, Via Diotisalvi 2, 56100 Pisa, Italy.
}

(Received April 15, 1980)

\begin{abstract}
The possibility of synthesizing two- or three-block copolymers between styrene and isobutylene via a direct cationic polymerization has been investigated. Previous studies had shown that the polymerization of these monomers with syncatalytic systems composed of aluminium organic compounds and chlorine are affected by transfer reactions, whereas terminations are almost absent. However, preliminary experiments have shown that the production of two- and three-block copolymers can be achieved to some extent, provided that appropriate experimental conditions leading to a substantial limitation of the importance of transfer reactions are adopted. A mathematical model has been developed which describes satisfactorily the polymerization pattern. This model is being used to determine, with the aid of a computer, the most convenient conditions for the production of block copolymers.
\end{abstract}

KEY WORDS Isobutylene / Styrene / Chlorine / Aluminium Organic / Compounds / Cationic Polymerization / Living Polymer / Block Copolymers / Mathematical Model /

Previous studies carried out in these laboratories had shown that the polymerization of isobutylene, initiated by syncatalytic systems, for example the $\mathrm{Et}_{2} \mathrm{AlCl}+$ chlorine system, is characterized by a reaction with a relatively slow start and by the absence of important termination reactions. ${ }^{1-8}$ Such polymerization presents kinetic characteristics similar to those belonging to "living polymerizations": further additions of monomer, in fact polymerize completely at a speed which decreases only slightly along the series of subsequent monomer additions, transfer reaction with the monomer is also absent. It had been demonstrated, however, that the molecular weight of the polymer obtained through the subsequent additions of monomer to the same system, increased only slightly with each successive addition. This indicated that the molecular weight of the polymer was regulated by transfer reactions with substances the concentrations of which are proportional mainly to the concentration of chlorine (or the $\mathrm{Me}_{3} \mathrm{CCl}$ ). However, it seemed interesting to study experimentally the possibility of obtaining, even though with limited yields, block polymers of the AB type, introducing at the end of the polymerization of the isobutylene, a monomer such as styrene, capable of bringing about a plastomeric block. Moreover if these catalytic systems should show the same behaviours for the polymerization of styrene, we could try to obtain new thermoplastic elastomers styrene-isobutylene-styrene by the successive polymerizations of these two monomers. The results of this research work, already described ${ }^{9}$ were partially successful in producing block copolymers.

During this work we discovered that in experiments carried out in $\mathrm{CH}_{2} \mathrm{Cl}_{2}$ a catalytic addition of isobutylene to a quiescent solution of styrene and $\mathrm{AlCl}_{3}$ causes a process of polymerization of styrene with quantitative yield and with an acceleration period. This polymerization seemed less dominated by transfer than that initiated by $\mathrm{Cl}_{2}+\mathrm{AlEt}_{2} \mathrm{Cl}$ system and this catalytic system has been also used to produce block copolymers between styrene and isobutylene. ${ }^{10}$ Very recently we have investigated the polymerization and copolymerization of styrene and isobutylene in homogeneous system using a mixture of two solvents, mainly heptane and $\mathrm{CH}_{2} \mathrm{Cl}_{2}$, with halogens and aluminium organic 
compounds as catalyst. High yield of block copolymers has been obtained in this case and a mathematical model has been very useful in order to choose the appropriate experimental conditions.

\section{SYNTHESIS OF TWO-BLOCK COPOLYMERS BETWEEN STYRENE AND ISOBUTYLENE}

Several experiments have been carried out in solution of a mixture of heptane and $\mathrm{CH}_{2} \mathrm{Cl}_{2}$ mainly in 50:50 ratio, in a temperature range between -30 to $-70^{\circ} \mathrm{C}$, in which two-block copolymers are obtained both by adding isobutylene at the end of a polymerization of styrene initiated by $\mathrm{Cl}_{2}+\mathrm{AlEt}_{2} \mathrm{Cl}$, and styrene at the end of a polymerization of isobutylene with the same catalytic system.

The relevant time-conversion and timeconductivity curves for these experiments are shown in Figure 1 and Figure 2, respectively. It is apparent

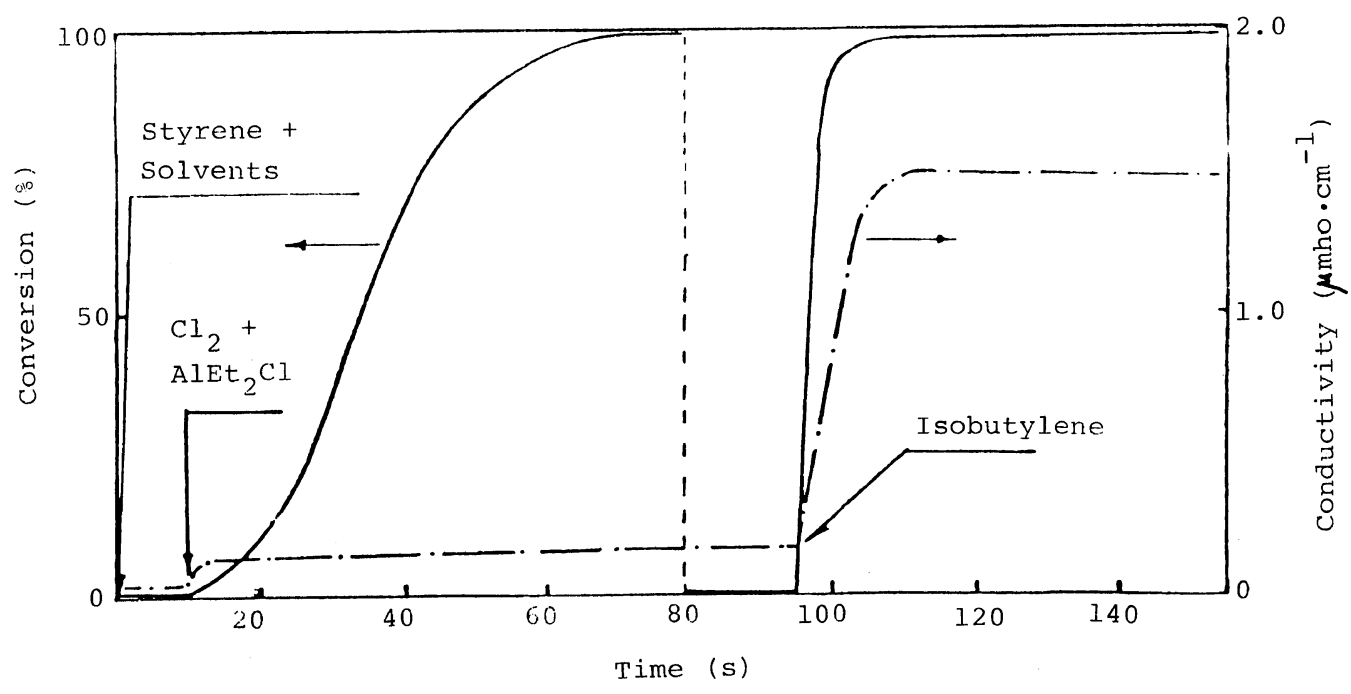

Figure 1. Synthesis of two-block copolymers styrene- $b$-isobutylene: $T,-50^{\circ} \mathrm{C}$; styrene, $0.1 \mathrm{M}$; isobutylene, $0.1 \mathrm{M} ; \mathrm{AlEt}_{2} \mathrm{Cl}, 1.3 \times 10^{-3} \mathrm{M} ; \mathrm{Cl}_{2}, 9 \times 10^{-4} \mathrm{M}$.

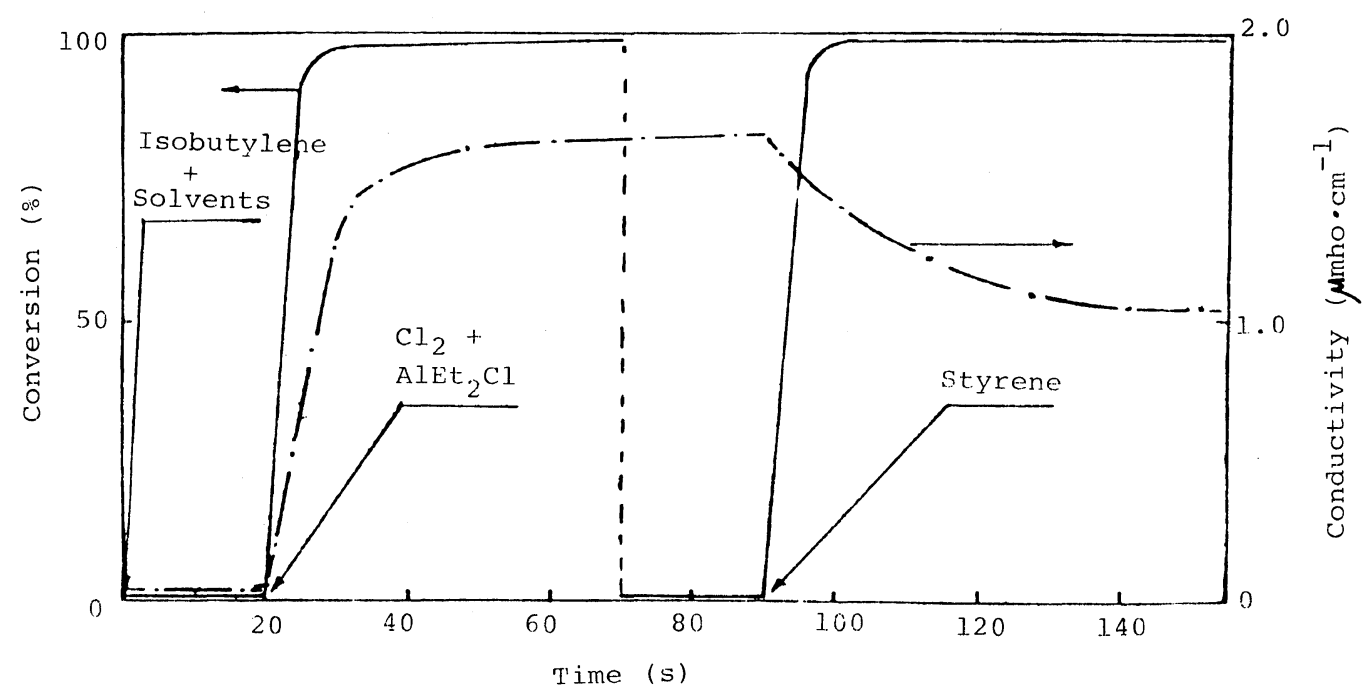

Figure 2. Synthesis of two-block copolymers isobutylene- $b$-styrene. Experimental conditions as in Figure 1. 
Block Copolymers Styrene-Isobutylene by Direct Route

Table I. Yield of two-block copolymers from styrene and isobutylene ${ }^{\mathrm{a}}$

\begin{tabular}{|c|c|c|c|c|c|c|}
\hline \multirow{2}{*}{$\begin{array}{c}\text { Exptl } \\
\text { no. }\end{array}$} & [Styrene] & [Isobutylene] & {$\left[\mathrm{Et}_{2} \mathrm{AlCl}\right] \times 10^{3}$} & {$\left[\mathrm{Cl}_{2}\right] \times 10^{4}$} & $T$ & Yield \\
\hline & $\mathbf{M}$ & $\mathbf{M}$ & $\mathbf{M}$ & $\mathbf{M}$ & ${ }^{\circ} \mathrm{C}$ & $\%$ \\
\hline $1^{\mathrm{b}}$ & 0.10 & 0.10 & 1.30 & 9.00 & -30 & 30 \\
\hline $2^{b}$ & 0.10 & 0.10 & 1.30 & 9.00 & -50 & 49 \\
\hline $3^{b}$ & 0.10 & 0.10 & 1.30 & 9.00 & -70 & 60 \\
\hline $4^{\mathrm{c}}$ & 0.10 & 0.10 & 1.30 & 9.00 & -30 & 35 \\
\hline $5^{c}$ & 0.10 & 0.10 & 1.30 & 9.00 & -50 & 53 \\
\hline $6^{\mathrm{c}}$ & 0.10 & 0.10 & 1.30 & 9.00 & -70 & 65 \\
\hline
\end{tabular}

a Solvent, $\mathrm{CH}_{2} \mathrm{Cl}_{2}+\mathrm{C}_{7} \mathrm{H}_{16}$ (50:50 mixture).

b Order of addition of monomers: styrene, isobutylene.

c Order of addition of monomers: isobutylene, styrene.

that isobutylene added at the end of the styrene polymerization, polymerizes completely and without acceleration, and that the polymerization is accompanied by strong conductivity change. When styrene is added at the end of the isobutylene polymerization, it polymerizes completely without acceleration and the polymerization is very fast, while the conductivity, fairly high during the isobutylene polymerization, decreases progressively (Figure 2). Block copolymers are obtained also in this case.

The product thus obtained has been fractionated and characterized as already described, ${ }^{10}$ the yields of two-block copolymers were always high in the whole range of temperature investigated, as it is shown in Table I.

\section{SYNTHESIS OF THREE-BLOCK COPOLYMERS BETWEEN ISOBUTYLENE AND STYRENE (OR $\alpha, p$ - DIMETHYLSTYRENE)}

A further addition of styrene to the polymerization mixture obtained in the experiments carried out for the synthesis of two-block styrene-isobutylene copolymers, gives rise to a fast polymerization as it is shown in Figure 3 .

The reaction product obtained with the direct

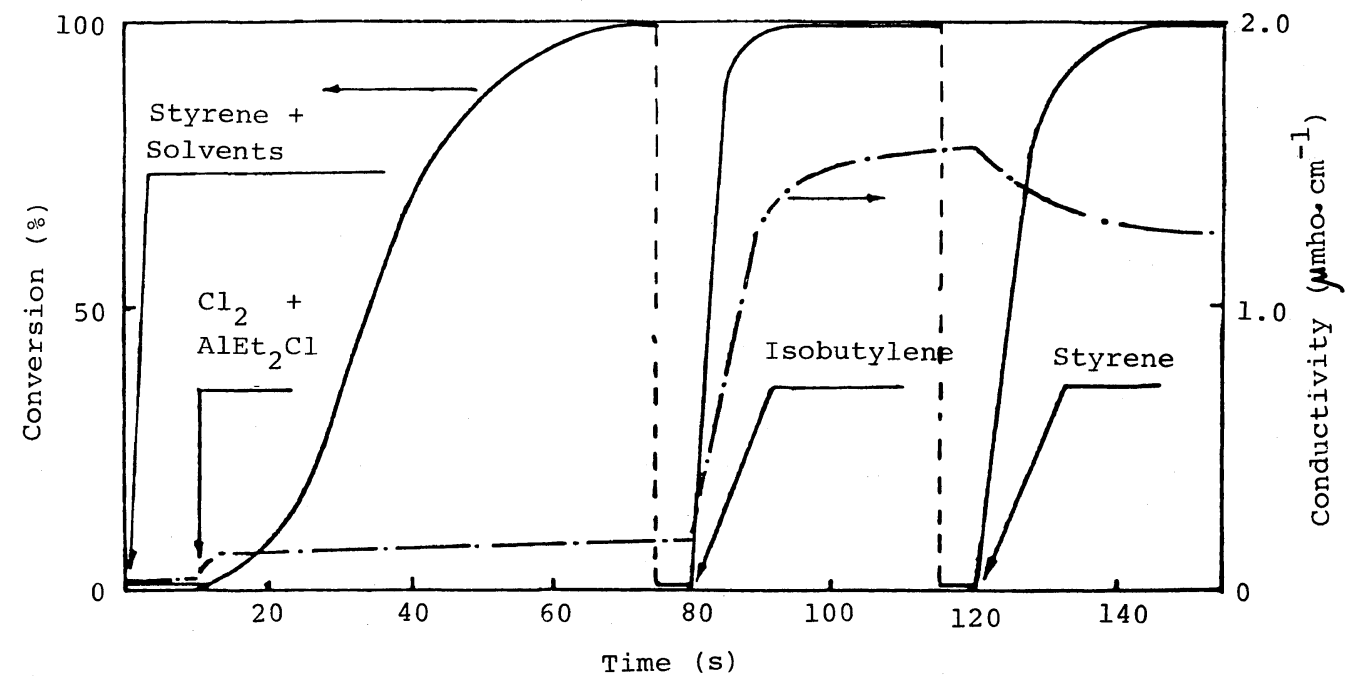

Figure 3. Synthesis of three-block copolymes styrene- $b$-isobutylene- $b$-styrene. Experimental conditions as in Figure 1. 


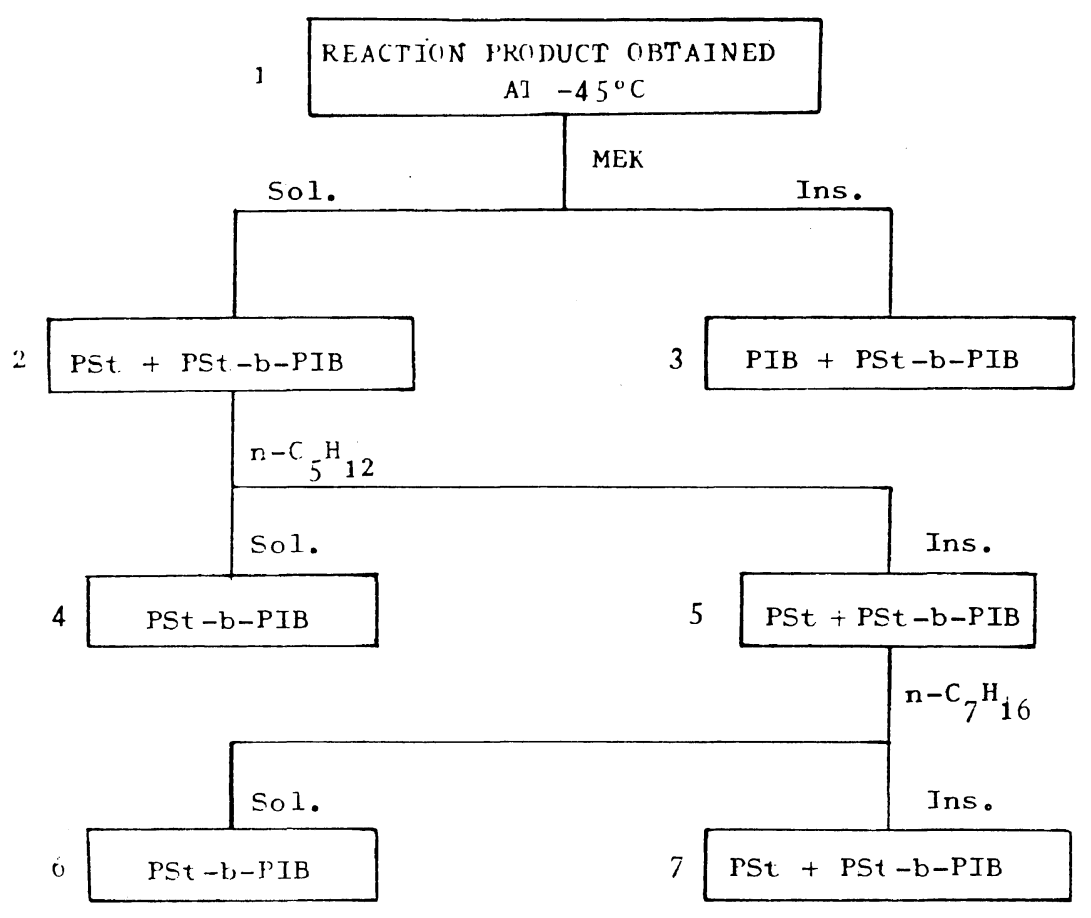

Figure 4. Extraction procedure to obtain pure two-(AB) and three-(ABA) block copolymers.

procedure just described was fractionated by Kennedy's method ${ }^{11}$ and is illustrated by Figure 4 .

It is apparent that with this fractionation it is not possible to separate three-block copolymer from two-block copolymer. Fractions 4 and 6 should not contain homopolymers, however.

The NMR analysis of fraction 7 shows that this fraction does not consist solely of styrene homopolymer but contains also some copolymer which might well be of the ABA type, since this copolymer is richer in styrene than the corresponding $\mathrm{AB}$ one.

The IR and NMR spectra of the samples obtained as fractions 4 and 6 in Figure 4 display all the characteristic absorptions of polystyrene and polyisobutylene and are very similar to that obtained from a blend of the two homopolymers, and do not differ markedly from the spectrum of a random copolymer of the same overall composition.

The fractionation procedure described in Figure 4 , on the other hand, rules out the possibility that these fractions may consist of a mixture of homopolymers, whereas the kinetics of polymerization clearly indicates that the samples cannot be random copolymers, since isobutylene was added to the system just after the end of the complete polymerization of styrene and the second styrene at the end of the complete polymerization of isobutylene.

We conclude therefore that fractions 4 and 6 consist mainly of $\mathrm{AB}$ and/or $\mathrm{ABA}$ block copolymers.

The IR and NMR spectra cannot prove the existence of three-block copolymer, but they are not inconsistent with it.

The DSC trace of fraction 6 of Figure 4 is qualitatively similar to those obtained with twoblock copolymers described previously. ${ }^{10}$ The only difference consists in the fact that the $T_{\mathrm{g}}$ associated with the elastomeric blocks and the $T_{\mathrm{g}}$ of the styrene block practically coincides now with that of isobutylene and styrene homopolymers. Although these differences do not provide a proof, they would be expected if fractions 4 and 6 should contain a three-block copolymer.

Circumstantial evidence in favour of the formation of some three-block copolymer by the procedure described in this paragraph is furnished also by molecular weight measurements and GPC 
analysis. The molecular weights of the products obtained with the procedure described in Figure 3 are invariably and appreciably higher than those of polymers obtained, under identical conditions of temperature and concentrations, with the procedure of Figures 1 and 2 which has been shown to produce two-block AB copolymers.
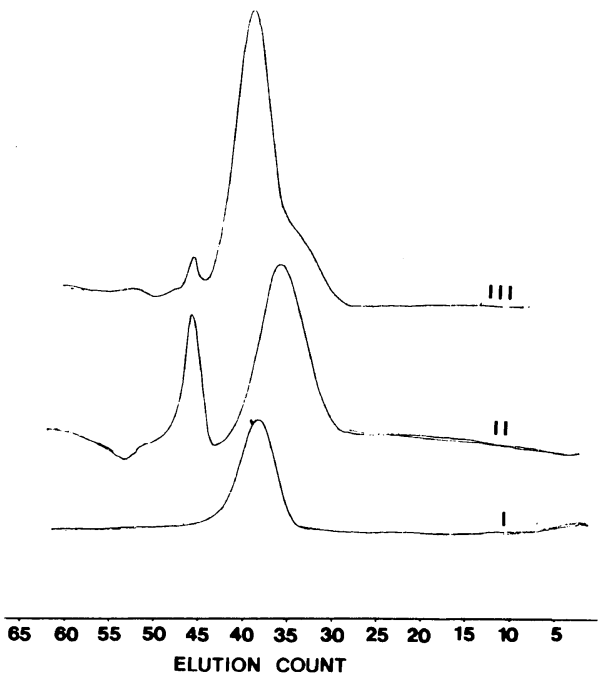

Figure 5. GPC traces of (I) polystyrene, (II) polyisobutylene, (III) mixture of (I) and (II). Samples obtained at $-50^{\circ} \mathrm{C}$ in a mixture of $\mathrm{CH}_{2} \mathrm{Cl}_{2}+\mathrm{C}_{7} \mathrm{H}_{16}(50: 50)$ with $\mathrm{Cl}_{2}, 9.0 \times 10^{-4} \mathrm{M}$ and $\mathrm{AlEt}_{2} \mathrm{Cl}, 1.3 \times 10^{-3} \mathrm{M}$.

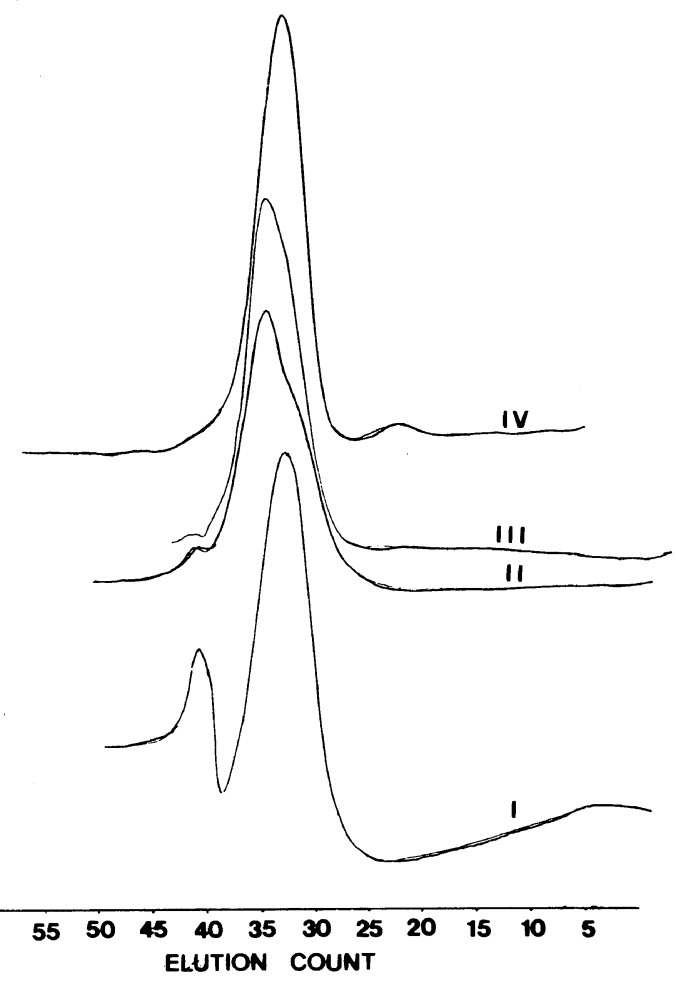

Figure 6. GPC traces of (I) ABA styrene (A)isobutylene (B) three-block copolymer, (II) fraction 2, (III) fraction 7, and (IV) fraction 6. Experimental conditions as in Table II.

Table II. Yield of three-blockyl copolymers (fractions $4+6$ in Figure 4) from styrene and isobutylene ${ }^{a}$

\begin{tabular}{|c|c|c|c|c|c|c|c|}
\hline \multirow{2}{*}{$\begin{array}{c}\text { Exptl } \\
\text { no. }\end{array}$} & [Styrene $_{1}$ & [Isobutylene] & {$[\text { Styrene }]_{2}$} & {$\left[\mathrm{Et}_{2} \mathrm{AlCl}\right] \times 10^{3}$} & {$\left[\mathrm{Cl}_{2}\right] \times 10^{4}$} & $T$ & Yield \\
\hline & $\mathbf{M}$ & $\mathbf{M}$ & $\mathbf{M}$ & $\mathbf{M}$ & $\mathbf{M}$ & ${ }^{\circ} \mathrm{C}$ & $\%$ \\
\hline 1 & 0.10 & 0.10 & 0.10 & 1.30 & 9.00 & -30 & 32 \\
\hline 2 & 0.10 & 0.10 & 0.10 & 1.30 & 9.00 & -50 & 47 \\
\hline 3 & 0.10 & 0.10 & 0.10 & 1.30 & 9.00 & -70 & 55 \\
\hline
\end{tabular}

a Solvent, $\mathrm{CH}_{2} \mathrm{Cl}_{2}+\mathrm{C}_{7} \mathrm{H}_{16}(50: 50$ mixture).

Table III. Yield of three-block copolymers (fractions $4+6$ in Figure 4) from styrene, isobutylene, and $\alpha, p$-dimethylstyrene ${ }^{\mathrm{a}}$

\begin{tabular}{|c|c|c|c|c|c|c|c|}
\hline \multirow{2}{*}{$\begin{array}{c}\text { Exptl } \\
\text { no. }\end{array}$} & [Styrene] & [Isobutylene] & {$[\alpha, p$-Dimethylstyrene] } & {$\left[\mathrm{Et}_{2} \mathrm{AlCl}\right] \times 10^{3}$} & {$\left[\mathrm{Cl}_{2}\right] \times 10^{4}$} & $T$ & Yield \\
\hline & $\mathbf{M}$ & $\mathbf{M}$ & $\mathbf{M}$ & $\mathbf{M}$ & $\mathbf{M}$ & ${ }^{\circ} \mathrm{C}$ & $\%$ \\
\hline 1 & 0.10 & 0.10 & 0.10 & 1.30 & 9.00 & -30 & 25 \\
\hline 2 & 0.10 & 0.10 & 0.10 & 1.30 & 9.00 & -50 & 40 \\
\hline 3 & 0.10 & 0.10 & 0.10 & 1.30 & 9.00 & -70 & 49 \\
\hline
\end{tabular}

a Solvent, $\mathrm{CH}_{2} \mathrm{Cl}_{2}+\mathrm{C}_{7} \mathrm{H}_{16}(50: 50$ mixture $)$. 
The GPC traces are reported in Figures 5 and 6. The trace of fraction 6 shows only one symmetric peak and is different from those of the two homopolymers and of the mixture (Figure 5) as well as from those of fractions 2 and 7 and from that of the unfractionated copolymer. The GPC analysis of the polymers is still in progress. This result has been confirmed by the synthesis with the same procedure of $\mathrm{ABC}$ three-block copolymers styrene, isobutylene and $\alpha, p$-dimethylstyrene. The yields of three-block copolymers are fairly high in the whole range of temperature investigated, as it is shown in Tables II and III.

\section{MATHEMATICAL MODEL}

The possibility that three-block copolymers, containing polyisobutylene as the central elastomeric part, are obtained via a direct route requires that the polymerization of isobutylene has a living or nearly living character.

Since it is known that, with these syncatalytic systems, the polymerization is affected by transfer reactions, it is important to determine the conditions by which the extent of these reactions can be minimized.

To this end a mathematical model has been developed which differs from the kinetic scheme already proposed ${ }^{8}$ only for the initiation reaction.

The initiation reaction formerly assumed, i.e.,

$$
\mathrm{Et}_{2} \mathrm{AlCl}+\mathrm{Cl}_{2} \stackrel{k_{\mathrm{i}}}{\longrightarrow} \stackrel{+}{\mathrm{C}} 1 \cdot \mathrm{Et}_{2} \overline{\mathrm{A}} 1 \mathrm{Cl}_{2}
$$

could not explain why the conductivity increases with time following an S-shaped curve.

It is now assumed that the initiation consists of the following series of reactions.

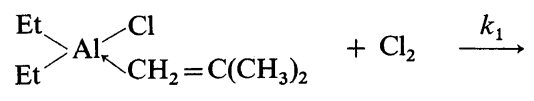

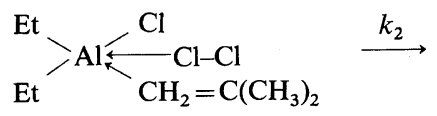

$$
\begin{aligned}
& \mathrm{ClCH}_{2}-\stackrel{+}{\mathrm{C}}\left(\mathrm{CH}_{3}\right)_{2}+\mathrm{Et}_{2} \overline{\mathrm{AlCl}}{ }_{2}
\end{aligned}
$$

Since the polymerization procedure consists of the addition of chlorine to a quiescent mixture of monomer and $\mathrm{Et}_{2} \mathrm{AlCl}$ in $\mathrm{CH}_{3} \mathrm{Cl}$, it can be safely assumed that the monomer- $\mathrm{Et}_{2} \mathrm{AlCl}$ complex involved in the first step of eq 2 has already reached the equilibrium concentration according to eq 3 when the polymerization is started.

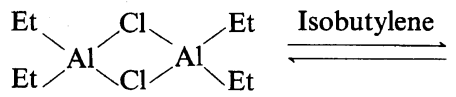

$$
\begin{aligned}
& 2 \stackrel{\mathrm{Et}}{\mathrm{Et}^{-}-\mathrm{Al}_{\nwarrow}}-\mathrm{Cl}
\end{aligned}
$$

Since isobutylene is present in a large excess it can also be assumed that the concentration of the complex equals the initial concentration of $\mathrm{Et}_{2} \mathrm{AlCl}$. Let us indicate this complex as AlM; the complex isobutylene- $\mathrm{Et}_{2} \mathrm{AlCl}$-chlorine formed in the first of eq 2 as $\mathrm{AlMCl}_{2}$; the propagating species, independent of the number of monomer units, as $\mathrm{P}^{+}$; the dead polymer molecules as $P$.

The model is then described by the following reactions,

Initiation:

$$
\mathrm{AlM}+\mathrm{Cl}_{2} \stackrel{k_{1}}{\longrightarrow} \mathrm{AlMCl}_{2} \stackrel{k_{2}}{\longrightarrow} \mathrm{P}^{+}
$$

Propagation:

$$
\mathrm{P}^{+}+\mathrm{M} \stackrel{k_{\mathrm{p}}}{\underline{\mathrm{P}^{+}}}
$$

Transfer:

$$
\begin{aligned}
& \mathrm{P}^{+}+\mathrm{AlM} \underset{\mathrm{trAl}}{\stackrel{k_{\mathrm{trCl}}}{\longrightarrow}} \mathrm{P}+\mathrm{P}^{+} \\
& \mathrm{P}+\mathrm{P}^{+}
\end{aligned}
$$

For computer calculations the following symbols have been used to indicate the concentrations of the different species and the rate constants shown in brackets: CL2 (chlorine), AL1 (AlM), AL2 $\left(\mathrm{AlNCl}_{2}\right), \mathrm{M}$ (isobutylene), $\mathrm{P}^{+}$(propagating species), $\mathrm{P}\left(\right.$ dead polymer molecules), KP $\left(k_{\mathrm{p}}\right), \mathrm{K} 1\left(k_{1}\right), \mathrm{K} 2$ $\left(k_{2}\right), \mathrm{KI}\left(k_{\mathrm{i}}\right), \operatorname{KTRAL}\left(k_{\mathrm{trAl}}\right), \operatorname{KTRCl}\left(k_{\mathrm{trCl}_{2}}\right)$, and $\mathrm{KT}\left(k_{\mathrm{t}}\right)$.

The same symbolism is maintained in the following.

The differential equations are:

$$
\begin{aligned}
& \frac{\mathrm{dM}}{\mathrm{dt}}=-\mathrm{KP} \cdot \mathrm{M} \cdot \mathrm{P}^{+} \\
& \frac{\mathrm{dP}^{+}}{\mathrm{dt}}=\mathrm{K} 2 \cdot \mathrm{AL} 2 \\
& \frac{\mathrm{dAL} 2}{\mathrm{dt}}=\mathrm{K} 1 \cdot \mathrm{AL} 1 \cdot \mathrm{CL} 2-\mathrm{K} 2 \cdot \mathrm{AL} 2
\end{aligned}
$$


Table IV.

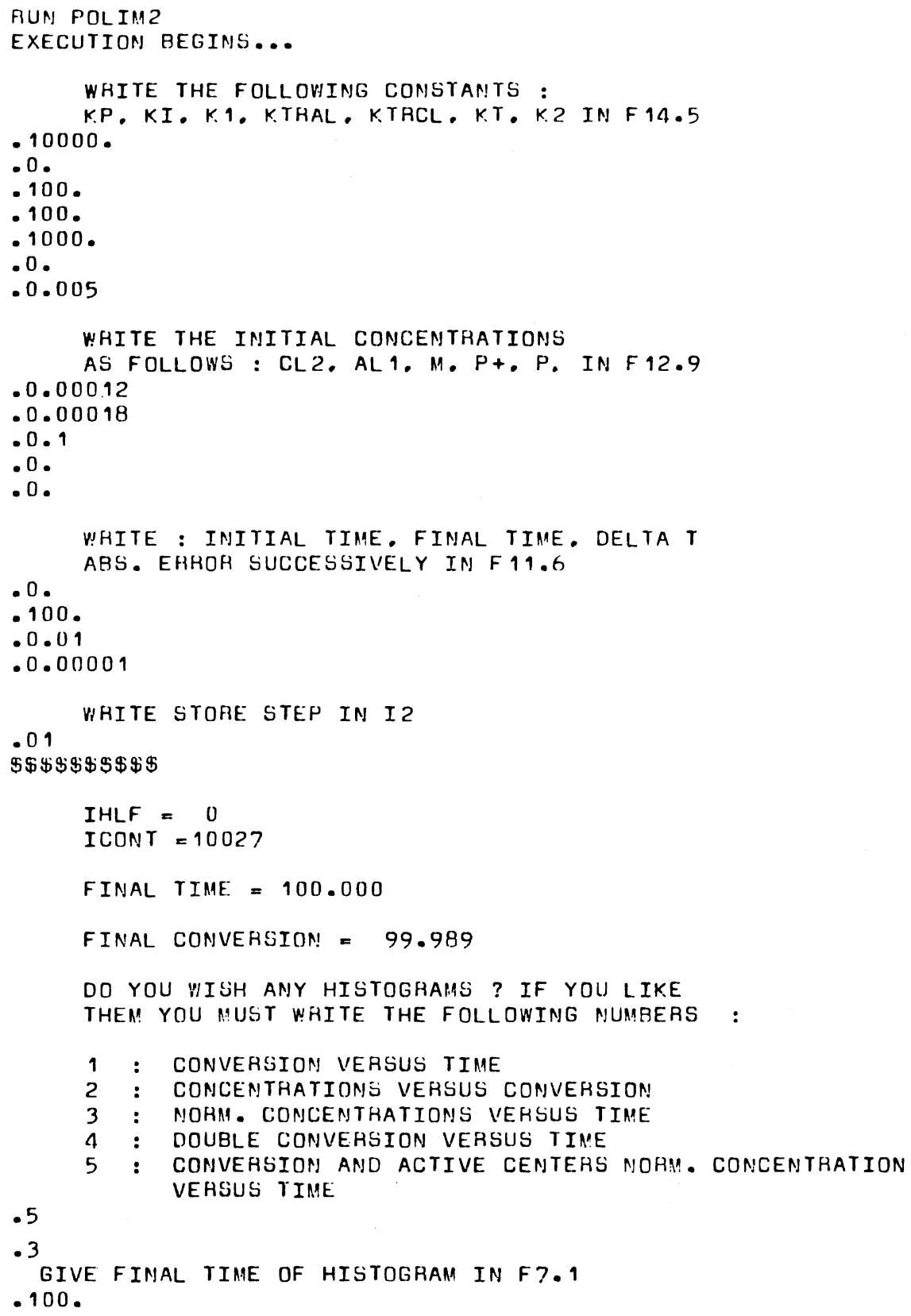


Table V.

\begin{tabular}{rll} 
MOOE & \multicolumn{1}{c}{ INITIAL } & FINAL \\
TIME & 0.0 & $0.10000 E+03$ \\
CL2 & $0.12000 E-03$ & $0.13495 E-04$ \\
AL 1 & $0.18000 E-03$ & $0.94443 E-04$ \\
M! & $0.10000 E+00$ & $0.11235 E-04$ \\
$P+$ & 0.0 & $0.21867 E-04$ \\
$P$ & 0.0 & $0.10056 E-04$ \\
CONV. & 0.0 & $0.99989 E+02$
\end{tabular}

IF YOU VIANT TO PHINT CONCENTRATION VALUES GIVE NUMBER 1

.0

IF YOU LIKE TO CONTINUE THE POLYMERIZATION! GIVE NUMBER 1

$\cdot 1$

GIVE FINAL TIME IN F 7.5

GIVE INITIAL MONOMER CONCENTRATION IN F 10.7 .100 . .0 .1 .01

V!RITE STOFE STEP IN I2

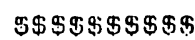

IHLF $=0$

ICONT $=1002 ?$

FINAL TIME $=100.000$

FINAL CON!VERSION $=100.000$

DO YOU WISH AN!Y HISTOGHAMS ? IF YOU LIKE

THEM YOU MUST WIRITE. THE FOLLOWING NUMBERS :

1 : CONVERSION VERSUS TIME

2 : CONCENTRATIONS VERSUS CONVERSION

3 : MORM. CONCENTRATIONS VERSUS TIME

4 : DOUBLE CONVERSION VERSUS TIME

5 : CONVEHSION AND ACTIVE CENTERS NORM. CONCEN!THATION

.4 VERSUS TIME 
Block Copolymers Styrene-Isobutylene by Direct Route

Table VI.

\begin{tabular}{lll} 
MODE & \multicolumn{1}{c}{ INITIAL } & FINAL \\
TIME & 0.0 & $0.10000 E+03$ \\
CL2 & $0.13895 E-04$ & $0.21359 E-06$ \\
AL 1 & $0.94443 E-04$ & $0.64829 E-04$ \\
$M$ & $0.10000 E+00$ & $0.21422 E-15$ \\
$P+$ & $0.21867 E-04$ & $0.43872 E-04$ \\
$P$ & $0.40056 E-04$ & $0.76576 E-04$ \\
CONV. & 0.0 & $0.10000 E+03$
\end{tabular}

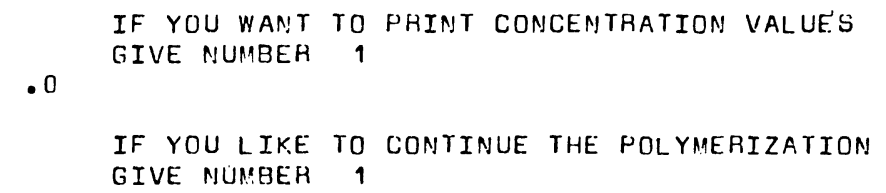




\section{P. GiUSTI}

Table VII.

$$
\begin{array}{cll}
\text { MODE } & \multicolumn{1}{c}{\text { INITIAL }} & \text { FINAL } \\
\text { TIME } & 0.0 & 0.10000 E+03 \\
\text { CL2 } & 0.21359 E-06 & 0.75340 E-09 \\
\text { AL } 1 & 0.64829 E-04 & 0.38697 E-04 \\
\text { M } & 0.10000 E+00 & 0.0 \\
P+ & 0.43872 E-04 & 0.57347 E-04 \\
P & 0.76576 E-04 & 0.10260 E-03 \\
\text { CONV } & 0.0 & 0.10000 E+03
\end{array}
$$

IF YOU WIANT TO PHINT CONCENTHATION! VALUES GIVE NUMBER 1

- 0

IF YOU LIKE TO CONTINUE THE POLYMERIZATION! GIVE NUMEER 1

.0

IF YOU ツ.ANT TO CHANGE CONCENTRATION

VALUES GIVE NUMBEH 1 .FOR TIME CHANGIN!G GIVE NUMBER 2 .0

A: 
Block Copolymers Styrene-Isobutylene by Direct Route

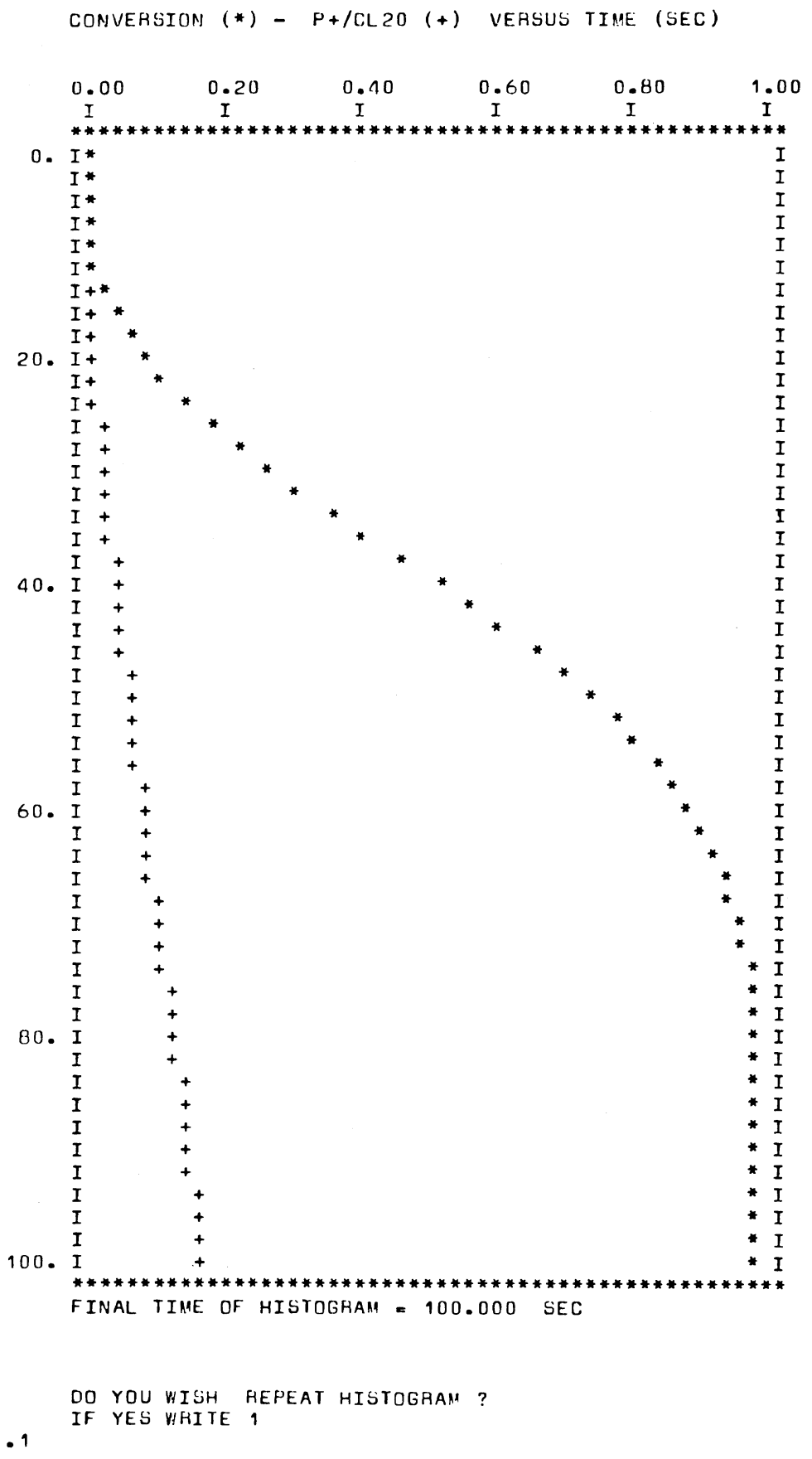

Figure 7. 


\section{P. GiUstI}

NORM - CONCERTRATJONS VEHEULS TIME

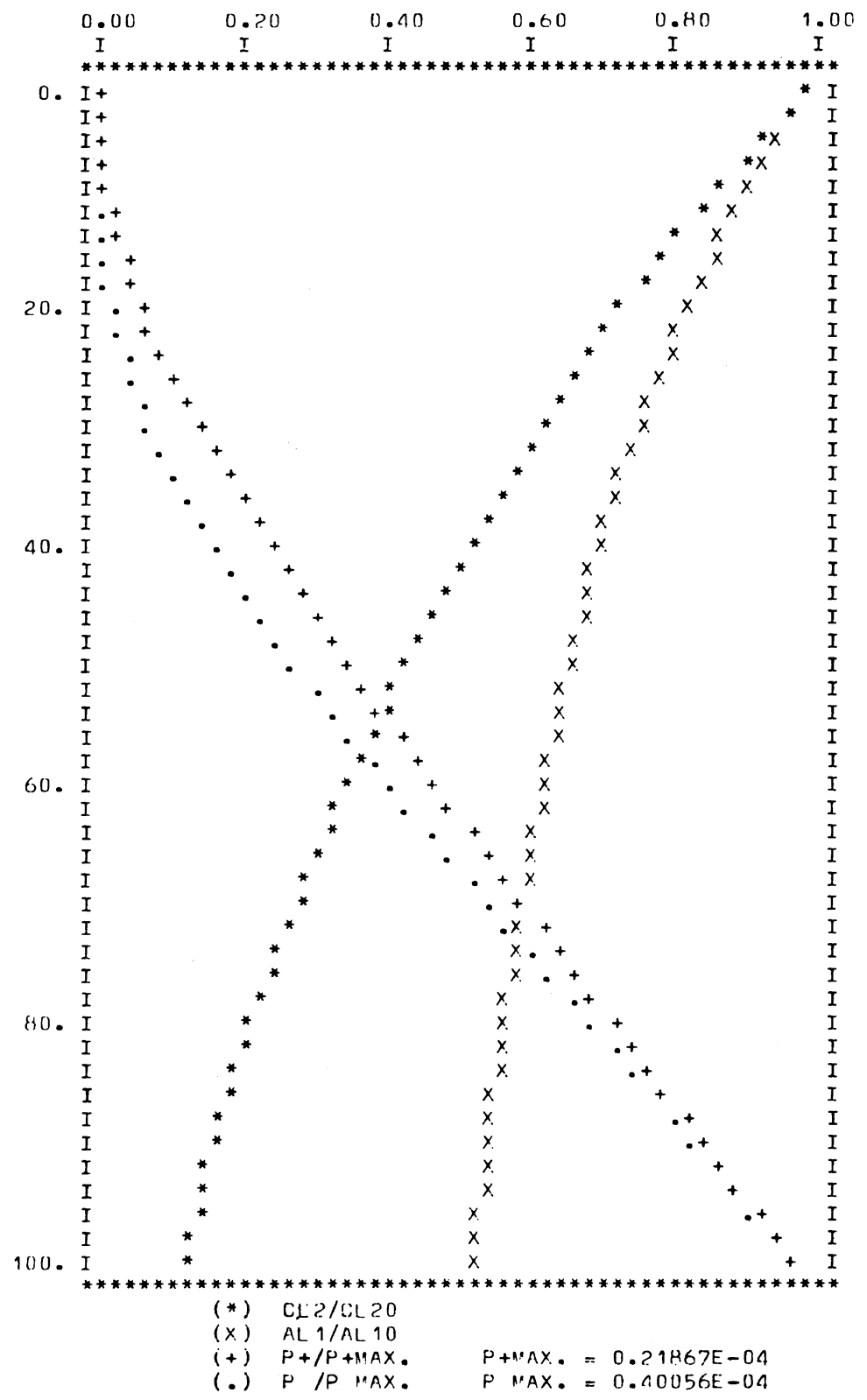

FINAL TIME $=100.000$ SEC.

IIO YOL WISH AEPEAT HISTOGHAM ? IF YES V'HITE 1

Figure 8. 
Block Copolymers Styrene-Isobutylene by Direct Route

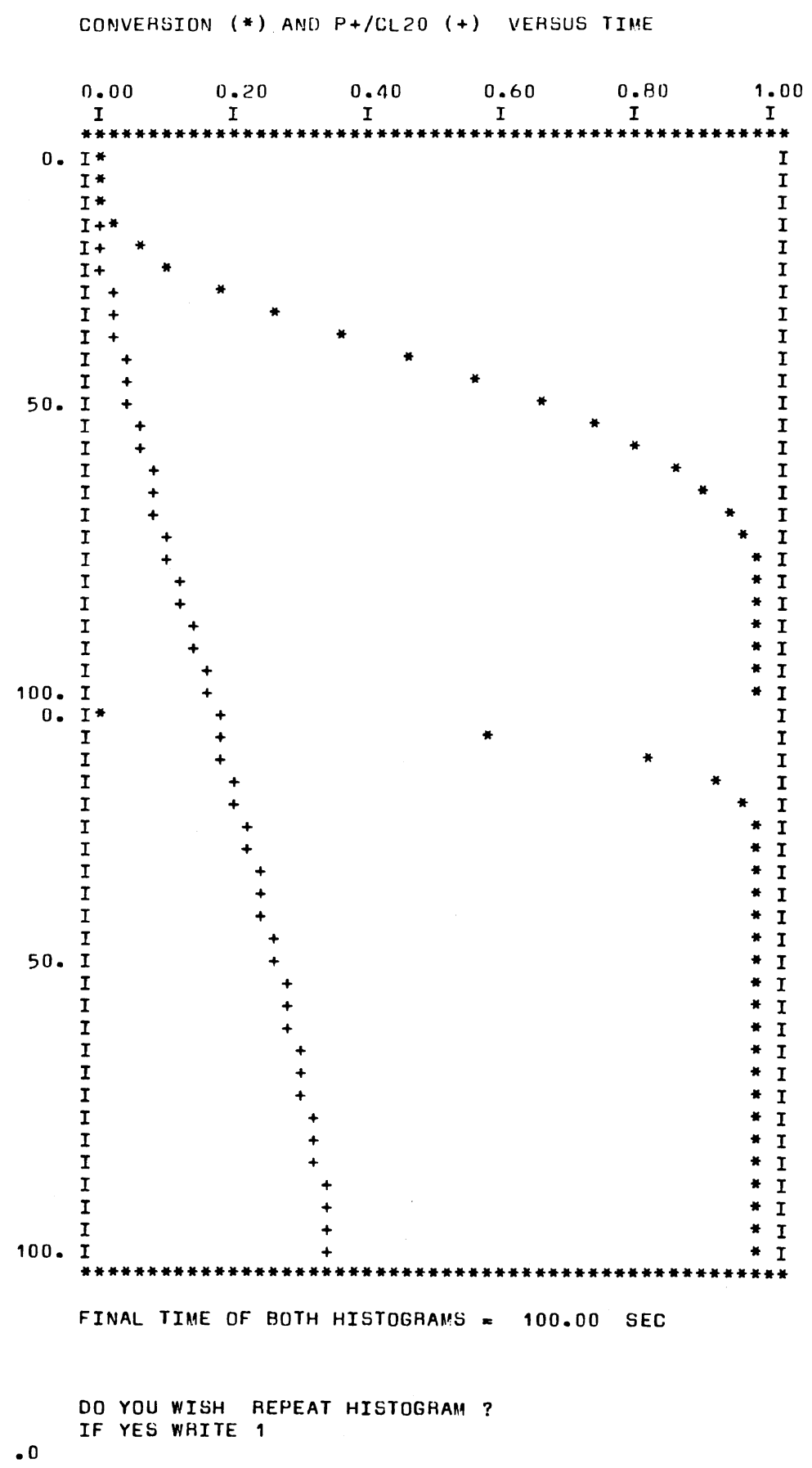

Figure 9. 


\section{P. GiustI}

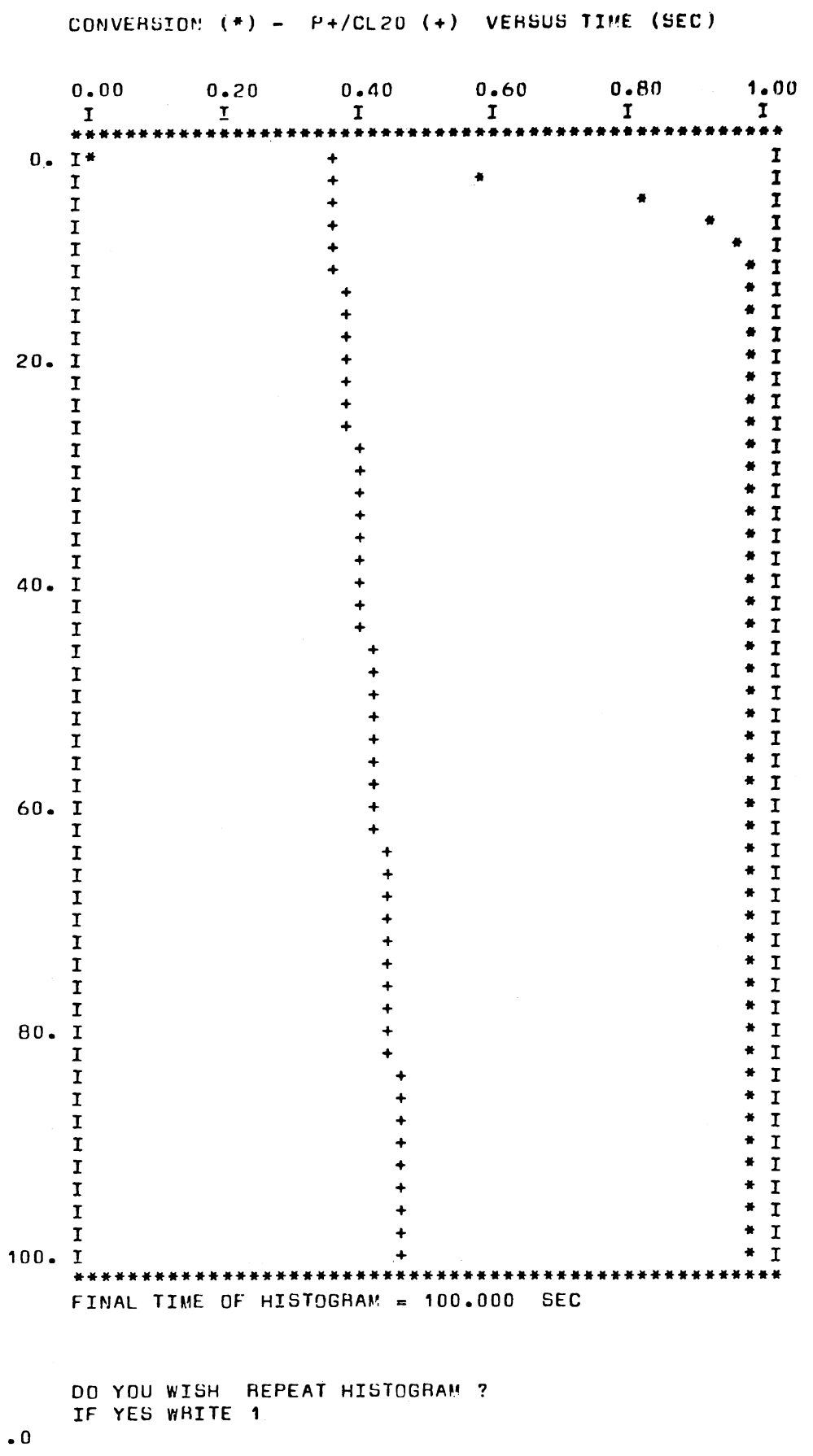

Figure 10. 


$$
\begin{aligned}
& \frac{\mathrm{dP}}{\mathrm{dt}}=(\mathrm{KTRAL} \cdot \mathrm{AL} 1+\mathrm{KTRCL} \cdot \mathrm{CL} 2) \mathrm{P}^{+} \\
& \frac{\mathrm{dAL} \overline{1}}{\mathrm{dt}}=-\mathrm{K} 1 \cdot \mathrm{AL} 1 \cdot \mathrm{CL} 2-\mathrm{KTRAL} \cdot \mathrm{AL} 1 \cdot \mathrm{P}^{+}
\end{aligned}
$$

$$
\frac{\mathrm{dCL} 2}{\mathrm{dt}}=-\mathrm{K} 1 \cdot \mathrm{AL} 1 \cdot \mathrm{CL} 2-\mathrm{KTRCL} \cdot \mathrm{CL} 2 \cdot \mathrm{P}^{+}
$$

This set of differential equations has been solved and the plots of the concentration versus time for the different species involved in the polymerization have been obtained. In the following, (Tables IV, V, VI, VII, and Figures 7, 8, 9, 10) the results obtained in the particular case of a set of experiments carried out with initial monomer, $\mathrm{Et}_{2} \mathrm{AlCl}$ and $\mathrm{Cl}_{2}$ concentrations, chosen in the range of values usually employed in previous studies, ${ }^{5}$ are given as an example.

The imput values of the propagation and transfer rate constants (Table III) are those already estimated independently in our previous work, ${ }^{8}$ while $\mathrm{K} 1$ and $\mathrm{K} 2$ are those resulting from the hypothesis that the final concentration of active centers were equal to that obtainable from eq 1 using the value of KI determined experimentally. ${ }^{8}$ Interestingly the best value of $\mathrm{K} 2$ is quite low; this is not surprising since the second step of eq 2 is not very different from the self-dissociation of the $\mathrm{Et}_{2} \mathrm{AlCl}$, which has been shown by us $^{8}$ to have a forward rate constant even lower.

Figure 7 shows the plots of the conversion and the active centers concentrations versus time elaborated by the computer using the imput data reported in Table III. The agreement between these plots and those obtained experimentally ${ }^{5}$ is excellent.

If a value of $\Lambda$ equal to $100\left(\mathrm{~S} \mathrm{~cm}^{-1} 1^{-1} \mathrm{~mol}^{-1}\right)$ is assumed for $\mathrm{p}^{+}$and the specific conductivity $\chi$ $\left(\mathrm{Scm}^{-1}\right)$ is obtained as $\mathrm{P}^{+} \Lambda / 1000$ the plot $\mathrm{P}^{+}$ versus time of Figure 7 practically coincides with that of $\chi$ versus time of Figure 2 of reference 5.

Figures, 9, 10 and Tables V, VI indicate that the adopted mathematical model also accounts for the pattern of the conversion-time and conductivitytime curves determined experimentally (Figure 13 of reference 5) for successive monomer additions.

In Figure 8 are reported the concentration of dead polymer molecules versus time as calculated on the basis of the model assumed. The comparison of Figure 8 with Figure 7, shows that the increase of the concentration of dead polymer molecules is much slower than that of the conversion, as it would be anticipated since the transfer reactions become progressively more important as polymerization proceeds.

The knowledge of the concentrations of dead polymer molecules and of active centers is clearly very useful for the choice of the most convenient conditions for the production of block copolymers.

\section{CONCLUDING REMARKS}

The results described in this lecture demonstrate, for the first time, that it is possible to synthesize three-block copolymers, between styrene and isobutylene via a direct cationic route. This goal has been achieved by means of an accurate kinetic analysis, although the polymerization system investigated were living only kinetically owing to the presence of transfer processes with species the concentration of which is related to the concentration of the components of the catalytic system.

Further developments are expected by an appropriate use of the mathematical model proposed.

\section{REFERENCES}

1. M. Baccaredda, M. Bruzzone, S. Cesca, M. DiMaina, G. Ferraris, P. Giusti, P. L. Magagnini, and A. Priola, Chim. Ind. (Milan), 55, 109 (1973).

2. A. Priola, G. Ferraris, M.DiMaina, and P. Giusti, Makromol. Chem., 176, 2271 (1975).

3. A. Priola, S. Cesca, G. Ferraris, and M. DiMaina, Makromol. Chem., 176, 2289 (1975).

4. P. Giusti, A. Priola, P. L. Magagnini, and P. Narducci, Makromol. Chem., 176, 2303 (1975).

5. S. Cesca, P. Giusti, O. L. Magagnini, and A. Priola, Makromol. Chem., 176, 2319 (1975).

6. S. Cesca, A. Priola, M. Bruzzone, G. Ferraris, and P. Giusti, Makromol. Chem., 176, 2339 (1975).

7. M. DiMaina, P. Giusti, G. Ferraris, and P. L. Magagnini, Makromol. Chem., 178, 2223 (1977).

8. P. L. Magagnini, S. Cesca, P. Giusti, M. DiMaina, and A. Priola, Makromol. Chem., 178, 2235 (1977).

9. P. Giusti, M. DiMaina, and P. Narducci, to be published.

10. M. DiMaina, P. Narducci, and P. Giusti, paper presented at the IUPAC Symposium on Macromolecules, Mainz, September, 1979.

11. J. P. Kennedy, S. C. Feinberg, and S. X. Huang, J. Polym. Sci., Polym. Chem. Ed., 16, 243 (1978). 